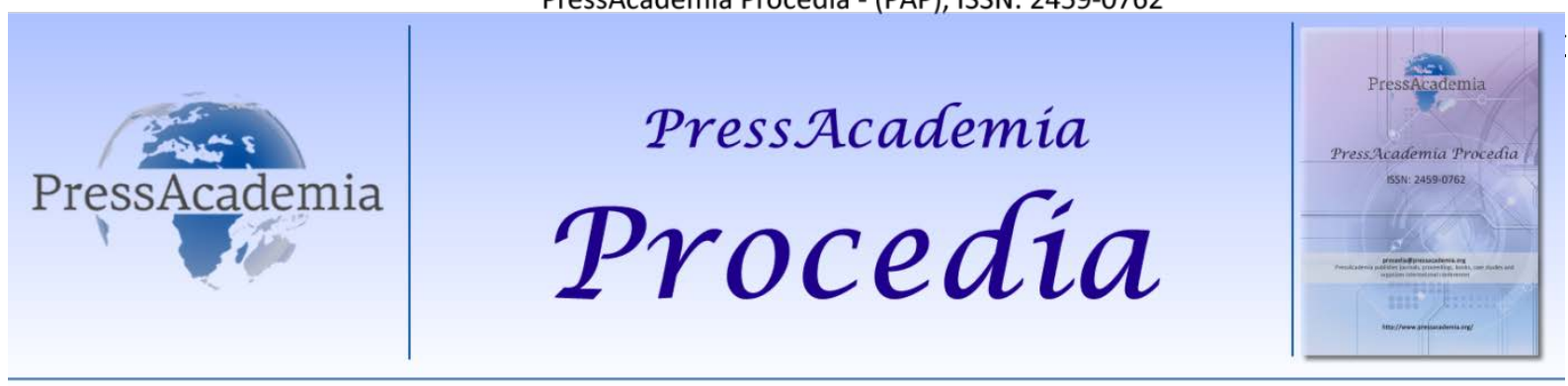

Global Business Research Congress (GBRC), May 26-27, 2016, Istanbul, Turkey.

\title{
A STRATEGIC ANALYSIS OF SMAC TECHNOLOGY
}

\section{DOI: 10.17261/Pressacademia.2016118684}

\author{
Naciye Guliz Ugur ${ }^{1}$, Tugba Koc ${ }^{2}$ \\ ${ }^{1}$ Sakarya University, ngugur@sakarya.edu.tr \\ ${ }^{2}$ Sakarya University, tcekici@sakarya.edu.tr
}

\begin{abstract}
In order to keep up with the next generation of technology and accommodate ever-increasing consumer demands for options, convenience, and, of course, the lowest prices, businesses must build their strategies on appropriate technology that can answer those demands. This paper will discuss the benefits, challenges, and implications of SMAC (social, mobile, analytics, cloud) technology and the effects of SMAC implementation on a business's enterprise architecture and IT.The research supports the utilization of social, mobile, analytics, and cloud (SMAC) technology to respond to consumer demands based on a review of the literature. Real-world considerations are offered to the reader on implementation and application of SMAC technology into today's business world.SMAC technology offers a state-of-the-art, adaptable enterprise solution that addresses these needs and can project a business's enterprise platform into today's modern economy. Although incorporating SMAC technology into an enterprise presents challenges, namely with security and high user expectations, the SMAC technology also offers a multitude of benefits. Effective change management, including assimilation of SMAC technology into an organization's culture, and communication at all levels of an organization are key to the successful implementation of the SMAC stack. Hurbean and Fotache's (2013) research concludes that businesses are wise to adopt "the third platform" of social media, mobility, big data, and cloud computing, and the authors of this paper agree with these findings based on the research conducted.
\end{abstract}

Keywords: Information services, technological change, SMAC, enterprise

JEL Codes: L36, O30, 033, 014

\section{INTRODUCTION}

Businesses today are faced with increasing challenges from consumer expectations, ongoing technological evolution, and the need to align business strategy accordingly to capture the market share in a virtual world with seemingly endless consumer choices. Particularly troublesome are consumers aged 35 years or younger known as the "milennials" who are accustomed to virtual experiences and interactions and demand that businesses keep up with their technical expectations (Frank, 2012, p. 15). The consumerization of IT and the increase in the number of individuals utilizing smart technology have also resulted in an increase in employees who wish to utilize their personal devices for work (Hurbean \& Fotache, 2013). The social, mobile, analytics, and cloud platform, also known as SMAC technology or the SMAC stack is a platform that provides businesses with the technology to meet these expectations (Frank, 2012). This manuscript will discuss the benefits, challenges, and implications of SMAC technology and the effects of SMAC implementation on a business's enterprise architecture and Information Technology (IT). According to Frank (2012), SMAC technology is the fifth wave of corporate technology architectures preceded by the mainframe, the minicomputer, client/server, and the internet. Advances such as web intelligence, web analytics, and the ability to obtain user-generated data have paved the way for new intelligence that capitalizes on consumer opinion and needs (Chen, Chiang, \& Storey, 2012). 


\section{LITERATURE REVIEW}

\subsection{SMAC Technology}

An ongoing challenge for organizations is keeping up with a changing customer base, and the key to maintaining a competitive advantage is innovative strategic planning. An organization's Chief Information Officer $(\mathrm{CIO})$ can utilize a SMAC strategy to stay competitive, differentiate the organization, and provide a great customer experience. The CIO charged with the development of IT and computer systems, can promote the implementation of SMAC technology in order to create more efficient IT processes, rework older processes, and find areas where new IT tools can be successfully introduced (Dewan et al., 2014). Data integrity and electronic data safety and responsibility, also a corporate responsibility of the $\mathrm{ClO}$, can be addressed through utilization of the cloud (Higgins \& Clark, 2013; Dewan et al., 2014).Social, mobile, analytics, and cloud are four technologies integrated into one central theme: social applications such as Facebook, Linkedln, Twitter, and Blogger and analytic applications such as financial, weather, and flight information are used on smart technologies and mobile data devices while the cloud can be accessed from mobile or desktop technology (Benedict, 2012; Cognizant, 2014).

\subsection{SMAC Opportunities And Challenges}

SMAC technology adds a new dimension to business model. Companies must embrace big data and predictive analytics to create multidimensional consumer profiles, and corporations can make more informed business decisions that better anticipate consumer needs, wants, and desires through the use of SMAC technology (Cognizant, 2014).

In addition to providing organizations with the ability to respond to consumer and employee demands for convenient mobile technology and customization, SMAC technology and its components provide other valuable data management solutions. Currently there are two trends that are impacting professionals from physicians to accountants and creating a paradigm shift in how content is delivered. The first trend is the extremely rapid increase of growth of the information industry. The second trend is the lack of professionals to absorb growing volumes of information while simultaneously serving increasing numbers of clients. These two mega trends put mounting pressure on professionals to be more productive with less. Business professionals want information that is interrelated and seek guidance, support, and insights that will help them improve their clients' outcomes. The technology required to reach these goals must move from a model of meta-tags and taxonomies to a model that is "discoverable" using natural language processing, text analytics, and domain expertise to make the content more "actionable".

The emergence of compliance clouds provides private storage for powerful informatics. The clouds analyze regulatory content rules, separate consumer-generated data, and enable the customer to avoid enterprise risks through compliance. To consider real-world application of the cloud, this new technology applied in financial institutions will enable risk management for fraud, liquidity, or credit risk. Additionally, smart sensors are being used to assist with emissions; such sensors in the environment can also improve efficiency in healthcare systems though monitoring tools that can check blood banks, food systems, refrigeration systems, and data centers and thus monitor potential risk and safety hazards. Secure clouds will store informatics and supply executive dashboards with data identified as posing risk (Information Security Community, 2013). The use of SMAC technology provides an answer for the rapidly growing, complex issue of data management (Hurbean \& Fotache, 2013).

Research reviewed by the authors revealed emerging strategies for Indian banks that include using SMAC technology for creative and cost-efficient operating models. Indian banks are considering the use of SMAC strategies to reach out to the urban and emerging classes in order to reinvigorate economic growth and rein in inflation during times of dwindling rupee value, weak global demand, and persistent current account deficits. The use of cloud services enables communication and collaboration for organizations such as the Mobile Payments Forum of India (MPFI) which consists of bank leaders, telecoms executives, technology providers, regulators, and government organizations (Bagchi, 2012). 
Despite its many benefits, SMAC technology creates potential concerns regarding employee access and use of social media and social networking applications while on the job. The Robert Half Technology Company conducted a poll of 1,400 companies concerning social network sites such as Facebook and Twitter usage while at work (Schiller, 2009). In the poll, ClOs were asked to put their company policies into categories: prohibited, business-only, limited use, or permission to use. The poll found that more than half of those surveyed prohibit the use of social networking sites while at work. Caution must be exercised for employees to use common sense and good judgment when engaging in social networking because ill-advised posts can become professional liabilities, even if made outside of business hours (Schiller, 2009). In order to reap the benefits that SMAC technology offers an organization, management must consider the ramifications of increased employee access to and use of social media in relation to their job duties.

\subsection{Organizational SMAC Implementation}

The world of technology is in an era where industries are continuously evolving using the latest technology, implementing and updating new systems, and offering access to the users from anytime and anywhere with easy- to-use web interface. The implementation of the latest technologies includes the social, mobile, analytics, and cloud services (Higgins \& Clark, 2013). SMAC is recognized and implemented to a particular organization's business processes and information systems in order to adopt social business strategy, mobile technology, and big data analytics and cloud computing. The SMAC implementation in an organization is a part of a social business strategy. SMAC embeds social IT with enterprise system to create collaboration with internal and external stakeholders through social networks. The Social Business Lens is a new feature and detonation that combines consumer-based technology with social applications that can be used in desktop or mobile web platforms such as Facebook, YouTube, Skype, etc. (Pearlson \& Saunders, 2013). The SMAC stack provides analytical tools and big data technologies such as OLAP and Business Intelligence for data warehousing, and embracing scalable and secured servers in cloud computing are giving organizations a new edge in technology where implementation is an interesting challenge (Higgins \& Clark, 2013). As part of a social IT platform that has the capability to evolve application processes, and strategic opportunity in an organization, SMAC implementation is a considerable approach to boost the value of the information system. Organizational SMAC implementation strategy denotes to aligning enterprise systems with business processes that renew enterprise architecture for human networking and the power of a fast and reliable application.

\subsection{Effects on It}

In order to better respond to internal business demands, keep organizations competitive, and provide better service to customers, the $\mathrm{CIOs}$ are responding to the SMAC approach; however, the information transformation, business processes, and data securities are becoming the priorities for SMAC technology. The effect on SMAC technology can be seen mostly in enterprise related IT systems. The overall management approach is to procure a data driven management system, and enterprise infrastructure can provide the platform to this kind of implementation (Frank, 2012). SMAC's effects on IT revolve around data-sharing processes inside and outside the organization, management and relationship of data among customers and partners, social interaction storage capacity and scalability, and updated information and security. The organization's performance depends on data and metrics; while data is collected through information systems, extracting the data and properly using the data adds value to the organization. The popularity of embracing the SMAC technology within an organization contributes $54 \%$ to performance measurement and analytics, and the concept to provide data anywhere, anytime contributes $34 \%$ to the mobile technology in SMAC adoption (Higgins \& Clark, 2013). The main effect on IT and big data is that the collection of the data should add value. The information system has to manage the data and extract the useful information in which case specialized computers and tools are needed to manage the data (Pearlson \& Saunders, 2013).

\subsubsection{Technical Expertise And Requirements}

The SMAC stack is a technology that cannot attach to the existing information system and business process with enhancement; in many cases a new model of IT infrastructure must be considered. Hurbean and Fotache (2013) suggest a seven-step "roadmap" for implementing a mobile IT project: align the project with the 
enterprise mobility strategy, analyze user workflow, select a mobile platform, select devices and operating systems, perform back-end integration, develop a mobile application, and deploy the mobile application. The organizations that want to implement SMAC technology should focus on uniting the business models to communicate with each other including all the stakeholders involved in the process. Additionally, managers and developers should identify the main information process areas where the convergence of new technologies and ways of working can truly benefit the business (Frank, 2012).

\subsubsection{Effects on Enterprise IT Groups}

The SMAC integration expands relationships with customers and partners of the organization (Higgins \& Clark, 2013). The use of big data sets, which is the collection of extreme data, runs in parallel servers with complex query and virtualization effects on the IT department to focus on data collection and value-added use of knowledge from software and hardware (Pearlson \& Saunders, 2013). To add value to the complex data, business intelligence analytics software and expertise are required. In addition to aligning business processes with IT integration and organizational strategy, a business case is written to develop data foundation, and a collaborative platform makes the data sharing relaxed. The internal and external data sharing within the organization leads to required resource sharing of information systems. The organization changes its culture to adopt knowledge to use value-added information. The overall SMAC process is scalable, updates frequently, and has data security embedded in the framework (Banerjee, 2013).

\subsubsection{API Platform Support}

To align business processes with information systems, the IT development team works with the functionality of business processes to put all of the applications, internal and external, in the same platform with data sharing compatibility. The API that adopts SMAC technology provides an interface where relevant applications can integrate and communicate. The most popular APIs currently are the HTTP-based web APIs (Banerjee, 2013). In a corporate setting, the information systems are mostly enterprise systems that follow the corporate guidelines and are sometimes government regulated. The enterprise systems' components (security, privacy, risks, and architecture) need to be managed within the organization's IT experts (Pearlson \& Saunders, 2013). Implementing and managing SMAC in enterprise systems requires a skilled workforce that will use the system to add value to the corporation and make an association with social network, end users' accessibility, and authentication in any mobile or stationary device flawless and secured.

\subsection{Effects on Enterprise Architecture}

The SMAC stack is considered the next master architecture for enterprise IT that will bind all business processes for inside and outside organizations and include all the business processes and data communication from all departments; the successful implementation will transform the business areas giving the enterprise system and the organization competitive advantages in data collecting, analytics, metrics, communication, social media and storage in the cloud (Frank, 2012).

\subsubsection{Operational Changes}

Organizations will rely on the changes of operational behavior to apply techniques to enhance business opportunities in the changing market and to stay ahead of the competition. Proper implementation and use of SMAC technology will cause business processes to use analytics for the improvement of sales, customer retention, performance measurement, and employee training. The organization's IT department has to participate in communication across organizational boundaries and interdepartmental business processes, and managerial aspects of the workflow must align with enterprise system functionality implementation and development. The organization in all sectors has to recognize the change in order to achieve an enhanced, stable-quality product measured with value-added data and analytics. The operational changes will be the acceptance of data-driven metrics and the measurement of quality in every aspect of organizational operations and end-of-business processes. 


\subsubsection{Cultural Changes}

The effects on the cultural changes for SMAC implementation depend on the features that will value the initiative of the technology investment. The industries that need customer interaction via different technologies like social network and mobile applications and data accessible from anywhere with secured authentication will experience positive culture changes and impact from the SMAC implementation (Chapala, 2013). Geographical context, the culture of a nation, and political and social influences on technology and organizations can also influence SMAC implementation. SMAC implementation's operational and cultural changes refer to the term called "gamification" (Bess, 2013, p. 31). Customers and employees are expecting a new style of commerce that includes the association of the SMAC technology. In this era, the next generation of business applications needs the methodology to increase the end user experience and maximize accessibility, productivity, and security as SMAC-enabled designs become the desired application paradigm and means of interaction (Evans, 2013).

\section{CONCLUSION}

SMAC technology offers a state-of-the-art, adaptable enterprise solution that addresses these needs and can project a business's enterprise platform into today's modern economy (Frank, 2012). Although incorporating SMAC technology into an enterprise presents challenges, namely with security and high user expectations, the SMAC technology also offers a multitude of benefits (Hurbean \& Fotache, 2013). SMAC technology (the cloud) securely addresses the paramount concern of managing exponentially growing data, including consumergenerated data, that is essential to the provision of the personal experiences desired by consumers (Higgins \& Clark, 2013). SMAC technology (the social) provides businesses with an opportunity to create brand awareness, vastly increase marketing potential, and respond rapidly to consumer demands (Bagchi, 2012). Effective change management, including assimilation of SMAC technology into an organization's culture, and communication at all levels of an organization are key to the successful implementation of the SMAC stack (Chapala, 2013). Hurbean and Fotache's (2013) research concludes that businesses are wise to adopt "the third platform" of social media, mobility, big data, and cloud computing, and the authors of this paper agree with these findings based on the research conducted.

\section{REFERENCES}

Bagchi, S. (2012). Mobile payment has a huge potential in India. Retrieved March 4, 2016 from www.cxotoday.com: http://www.cxotoday.com/story/mobile-payment-has-a-huge-potential-in-india/

Banerjee, S. (2013). How can API Platform Support the Integration of SMAC? Retrieved March 4, 2016 from www.cutter.com:https://www.cutter.com/article/how-can-api-platform-support-integration-smac-403586.

Benedict, K. (2012). Mobile Outlook 2012. Inside Research.

Bess, C. (2013). Gamification: Driving Behavior Change in the Connected World. Retrieved March 4, 2016 from www.cutter.com: https://www.cutter.com/article/gamification-driving-behavior-change-connected-world-417091

Chapala, N. (2013). Is SMAC Adding Business Value or More Complexity and Uncertainty. Retrieved March 4, 2016 from www.cutter.com: https://www.cutter.com/article/smac-adding-business-value-or-more-complexity-and-uncertainty-417081

Chen, H., Chiang, R., \& Storey, V. (2012). Business Intelligence and Analytics: From Big Data to Big Impact. MIS Quarterly, 36(4), 1-24.

Cognizant. (2014). Decoding Opportunity: Digital Business-Helping Clients Embrace the New Digital Customer. Cognizant.

Dewan, Bhushan, and Soumya Ranjan Jena. "The state-of-the-art of Social, Mobility, Analytics and Cloud Computing an empirical analysis." High Performance Computing and Applications (ICHPCA), 2014 International Conference on. IEEE, 2014.

Evans, $\mathrm{N}$ (2013) SMAC and the evolution of IT, Computerworld. Retrieved March 7, 2016 from http://www.computerworld.com/article/2475696/it-transformation/smac-and-the-evolution-ofit.html

Frank, M. (2012). Don't Get SMACked: How Social, Mobile, Analytics and Cloud Technologies are Reshaping the Enterprise. Cognizant.

Higgins, D., \& Sam, C. (2013). Leveraging Social Science to Boost Adoption of SMAC Technologies. Retrieved March 4, 2016 from www.cutter.com: https://www.cutter.com/article/leveraging-social-science-boost-adoption-smac-technologies-417071. 
Hurbean, L., \& Fotache, D. (2013). Mobile Technology: Binding Social and Cloud into a New Enterprise. Informatica Economica, 17(2), 7383.

Information Security Community. (2013). BYOD and Mobile Security. Information Security Community.

Pearlson, K. E., \& Saunders, C. S. (2013). Managing and Using Information Systems: A Strategic Approach, 5th Edition, New York, NY: Wiley.

Schiller, K. (2009). Employers Crack Down on Social Networking. Retrieved March 4, 2016 from www.questia.com: https://www.questia.com/magazine/1G1-211794496/employers-crack-down-on-social-networking 